\title{
Heavy Metals in Urban Soils of Xuzhou, China: Spatial Distribution and Correlation to Specific Magnetic Susceptibility
}

\author{
Xuesong Wang \\ Department of Chemical Engineering, Huaihai Institute of Technology, Lianyungang, China \\ Email: snowpine1969@126.com
}

Received October 17, 2012; revised December 17, 2012; accepted January 15, 2013

\begin{abstract}
The investigation of the anthropogenic contamination by heavy metals of soils is very important for environmental planning and monitoring in urban areas. In the present study, surface soils $(0-20 \mathrm{~cm})$ samples from 167 sampling sites in Xuzhou (China) were collected in 2010 and analyzed for heavy metals including $\mathrm{Zn}, \mathrm{Pb}, \mathrm{Fe}, \mathrm{Mn}, \mathrm{Cu}, \mathrm{Cd}, \mathrm{Sr}, \mathrm{Ba} \mathrm{Cr}$, $\mathrm{Ni}$ and Mo via inductively coupled plasma/mass spectrometry (ICP-MS). Compared with their levels in natural soils of China, these metals investigated exhibited a slight build-up in Xuzhou topsoils. The multivariate statistical analyses including factor analysis (FA) and cluster analysis (CA) were performed. The obtained results enabled the identification of two main groups of metals, discriminating $\mathrm{Ni}$, Mo and $\mathrm{Cr}$ from $\mathrm{Zn}, \mathrm{Pb}, \mathrm{Fe}, \mathrm{Mn}, \mathrm{Cu}, \mathrm{Cd}, \mathrm{Sr}$ and $\mathrm{Ba}$. Signifcant associations between $\mathrm{Pb}, \mathrm{Zn}, \mathrm{Fe}$ and specific magnetic susceptibility $(\chi)$ indicated that specific susceptibility can serve as proxies for these metals levels in Xuzhou urban soils.
\end{abstract}

Keywords: Heavy Metals; Spatial Distribution; Specific Magnetic Susceptibility; Urban Soils; Xuzhou

\section{Introduction}

Heavy metals continue to receive increasing attention due to the better understanding of their toxicological importance in ecosystems and human health. Urban soils are the "recipients" of large amounts of heavy metals from a variety of sources including industrial wastes, vehicle emissions, coal burning waste and other activities and accordingly have become an increasingly important environmental sampling medium for assessing anthropogenic heavy metals levels [1]. In China, heavy metal pollution in urban soils becomes serious with the rapid industrialization and urbanization during the last two decades [2]. Multiple studies on heavy metal contamination in urban soils have been conducted in several cities including Beijing [3], Changchun [4], Guangzhou [5], Hangzhou [6], Nanjing [7], Shanghai [8], Xuzhou [1,9], Shenyang [10], Hongkong [11,12], in past several years.

During recent years, measurement of magnetic susceptibility has become a general and accepted method to map pollution. Numerous studies have employed magnetic parameters, often exclusively specific susceptibility $(\chi)$ measurements, to provide a cost effective way to prospect for signs of industrial atmospheric particulate pollution [13 and references therein]. Many studies have linked anthropogenic magnetic enhancement with heavy metal contamination and significant positive correlations have been found [13-17]. Petrovsky et al. [14] have reviewed the associaiton between magnetic signals and metal concentrations from various sources. To the best of our knowledge, limited data have been reported on the relationships between heavy metals and specific susceptibility in Xuzhou urban soils [15].

Xuzhou is a highly industrialised city in China. We have reported the PAHs and black carbon containation in Xuzhou urban topsoils $[18,19]$. The objectives of the present study were 1) to characterize the $\mathrm{Zn}, \mathrm{Pb}, \mathrm{Cu}, \mathrm{Ba}$, $\mathrm{Ni}, \mathrm{Mo}, \mathrm{Cr}, \mathrm{Mn}, \mathrm{Cd}, \mathrm{Sr}$ and $\mathrm{Fe}$ concentrations in topsoils; 2) to examine the feasibility of using the magnetic susceptibility for the heavy metal pollution assessment of urban topsoils in Xuzhou.

\section{Materials and Methods}

\subsection{Study Area and Soil Samples}

The study area, the city of Xuzhou, is located in the north western part of Jiangsu, one of the provinces of China, the geographical position being $33^{\circ} 43^{\prime} \mathrm{N}$ to $34^{\circ} 58^{\prime} \mathrm{N}$, $116^{\circ} 22^{\prime} \mathrm{E}$ to $118^{\circ} 40^{\prime} \mathrm{E}$.

Surface soils $(0-20 \mathrm{~cm})$ were collected within the city of Xuzhou in 2010. Figure 1 shows the sampling sites. In total, 167 soil samples were collected; each consisting 


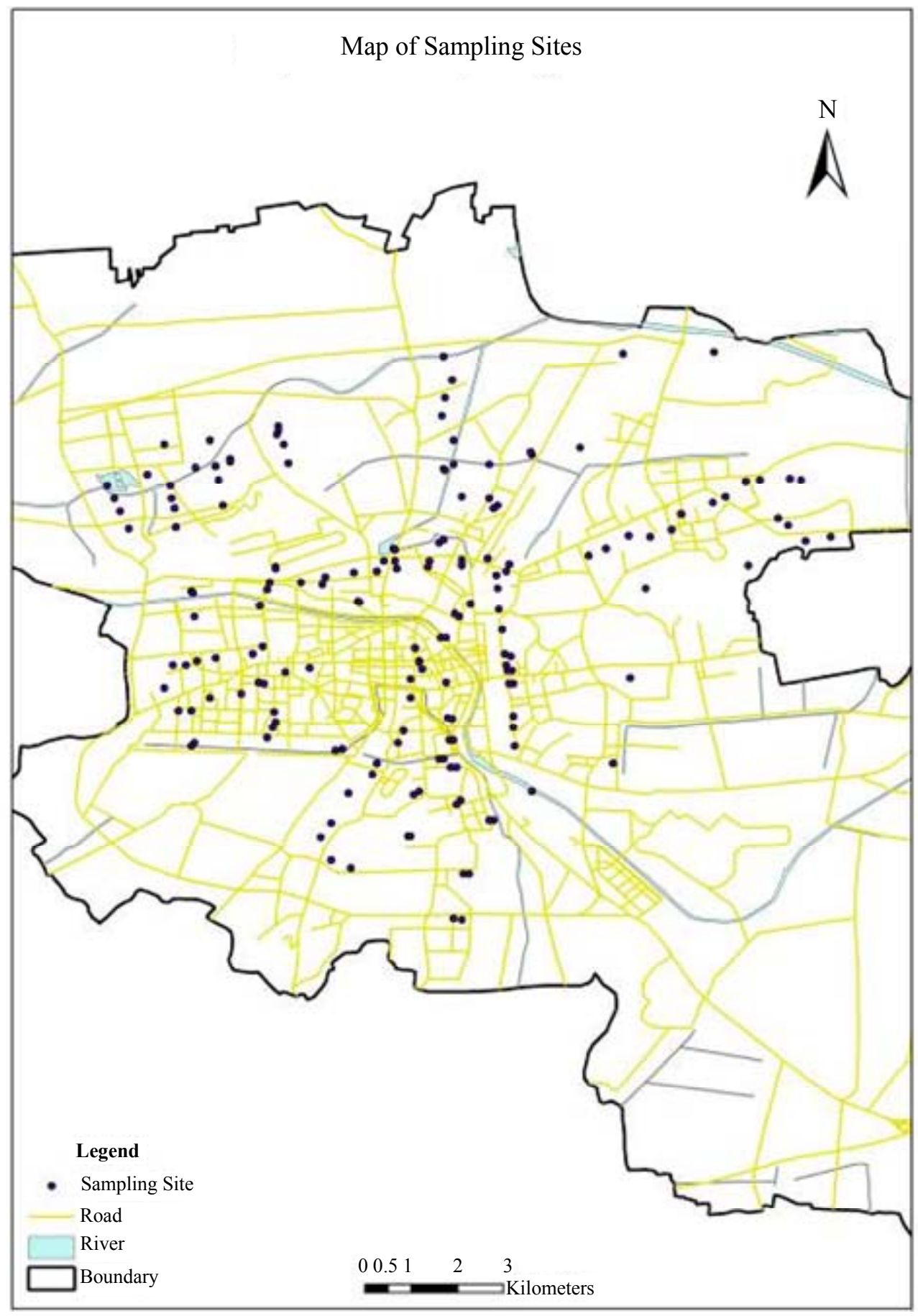

Figure 1. Map of soil sampling sites in Xuzhou.

of three subsamples collected from the surrounding area of each site (within $1 \mathrm{~m}^{2}$ ). All of the samples were freeze-dried and sieved to $<2 \mathrm{~mm}$ after removing stones and residual roots, then stored in desiccators.

\subsection{Determination of Heavy Metals}

One $0.2 \mathrm{~g}$ aliquot was completely dissolved with $\mathrm{HNO}_{3}$
$(5 \mathrm{ml}), \mathrm{HF}(5 \mathrm{ml})$ and $\mathrm{HClO}_{4}(3 \mathrm{ml})$ acid mixture for around $5 \mathrm{~h}$ on a hot plate and refluxed with the acid mixture if the sample was only partly dissolved. The residue was solubilized with $2 \% \mathrm{HNO}_{3}$ and diluted to volume. All reagents and acids (Fuchen, Shanghai) were suprapure or pro-analysis quality. $\mathrm{Zn}, \mathrm{Pb}, \mathrm{Fe}, \mathrm{Mn}, \mathrm{Cu}, \mathrm{Cd}$, $\mathrm{Sr}, \mathrm{Ba} \mathrm{Cr}, \mathrm{Ni}$ and Mo concentrations were measured by inductively coupled plasma-mass spectrometry (ICP- 
MS, Bruker 820-MS, Germany).

All glass- and plastic-wares were soaked overnight in a $10 \%$ nitric acid solution and rinsed thoroughly with deionized water before use. Precision and accuracy for HM concentrations were determined using certified reference materials (CRMs). Two soil samples (ESS-3, GSBZ50013-88 and ESS-4, GSBZ500014-88)) certified by the China Institute for Environmental Reference Materials (IERM) and a solution sample (GSB04-17672004) certified by the China National Centre of Analysis and Testing for Nonferrous Metals and Electronic Materials (NCATN) were used.

\subsection{Determination of Specific Susceptibility}

Magnetic susceptibility $\left(\chi, 10^{-8} \mathrm{~m}^{3} / \mathrm{kg}\right)$ was measured using a dual-frequency (470 and $4700 \mathrm{~Hz}$ ) Bartington Instruments MS2 susceptibility meter.

\subsection{Statistical Analysis}

The analytical results were compiled to form a multielemental database using SPSS 16.0 (Statistical Product and Service Solutions, SPSS Inc., USA). Statistical analyses including factor analysis (FA), cluster analysis (CA) and Pearson correlation analysis were performed using SPSS statistical software. In the FA, Varimax with Kaiser normalization was used as the rotation method in the analysis. Since the elemental concentrations varied greatly among the heavy metals, the raw data were standarded before the execution of clustering in CA. The data were standardized to the $\mathrm{Z}$ score (with a mean of 0 and a standard variation of 1 ) and then classified with the clustering method [20].

\section{Results and Discussion}

\subsection{Heavy Metal Concentrations in Urban Soils}

Table 1 presents summary statistics for the analyzed metals in all of the studied samples. In general, the concentrations of heavy metals were in wide ranges, which are typical in urban soils [20]. Compared with their levels [21] in natural soils of China also shown in Table 1, these metals investigated exhibited a slight build-up in Xuzhou topsoils. The median concentrations of $\mathrm{Ba}$ exceeded the target values recommended by the Dutch Ministry of Housing, Spatial Planning and Environment and those of $\mathrm{Cu}$ and $\mathrm{Zn}$ were close to the target values [22].

\subsection{Results of Statistical Analyses}

\subsubsection{Cluster Analysis (CA)}

The results of a cluster analysis of the 167 soil samples are illustrated with the dendrogram in Figure 2. The obtained results enabled the identification of two main groups of metals, discriminating $\mathrm{Ni}$, Mo and $\mathrm{Cr}$ from $\mathrm{Zn}$, $\mathrm{Pb}, \mathrm{Fe}, \mathrm{Mn}, \mathrm{Cu}, \mathrm{Cd}, \mathrm{Sr}$ and Ba. Previous study [1] has demostrated that heavy metals including $\mathrm{Zn}, \mathrm{Pb}, \mathrm{Cu}, \mathrm{Cd}$ and $\mathrm{Ba}$ were principally from anthropogenic contribution while metals $\mathrm{Ni}$ and $\mathrm{Cr}$ wre mainly from soil parental materials.

\subsubsection{Factor Analysis (FA)}

The results of the FA are presented in Table 2. In the analysis, two factors were extracted from the available dataset, explaining a total variance of approximately $63 \%$ (Table 2). Factor 1 is dominated by $\mathrm{Cr}$, Ni and Mo while Factor 2 is principally loaded by $\mathrm{Zn}, \mathrm{Pb}, \mathrm{Fe}, \mathrm{Mn}, \mathrm{Cu}, \mathrm{Cd}$, $\mathrm{Sr}$ and $\mathrm{Ba}$. The results of FA agree well with those of CA analysis.

\subsection{Spatial Analysis}

The spatial distribution of heavy metals in soils was analysed using the program SURFER 8 (Golden Software Inc.). The metal concentrations were first interpolated with the Kriging method. The spatial distribution of

Table 1. Summary stastistics of metal concentrations $(\mathrm{mg} / \mathrm{kg})$ and specific susceptibility $\left(\chi, 10^{-8} \mathrm{~m}^{3} / \mathrm{kg}\right)$ in Xuzhou urban topsoils and the guideline values $(n=167)$.

\begin{tabular}{|c|c|c|c|c|c|c|c|c|c|c|c|c|}
\hline & $\mathrm{Cr}$ & $\mathrm{Mn}$ & $\mathrm{Fe}$ & $\mathrm{Ba}$ & $\mathrm{Ni}$ & $\mathrm{Cu}$ & $\mathrm{Zn}$ & $\mathrm{Sr}$ & $\mathrm{Cd}$ & $\mathrm{Pb}$ & Mo & $\chi$ \\
\hline Mean & 73 & 459 & 28,202 & 531 & 34 & 34 & 169 & 198 & 0.58 & 37 & 3 & 234 \\
\hline Median & 54 & 459 & 26,531 & 430 & 25 & 31 & 132 & 201 & 0.43 & 32 & 1 & 157 \\
\hline Std. deviation & 8.4 & 8.3 & 7957 & 522 & 3.4 & 1.5 & 106 & 42.5 & 0.42 & 19.4 & 9.7 & 249 \\
\hline Min. & 8 & 303 & 16,300 & 249 & 14 & 15 & 51 & 73 & 0.17 & 13 & 0.3 & 37 \\
\hline Max. & 805 & 879 & 69,800 & 3929 & 337 & 111 & 815 & 325 & 2.75 & 126 & 109 & 1554 \\
\hline Background value & $61^{\mathrm{a}}$ & $583^{\mathrm{a}}$ & - & $469^{\mathrm{a}}$ & $26.9^{\mathrm{a}}$ & $22.6^{\mathrm{a}}$ & $72.4^{\mathrm{a}}$ & - & $0.097^{\mathrm{a}}$ & $26^{\mathrm{a}}$ & $2^{\mathrm{a}}$ & $38^{\mathrm{c}}$ \\
\hline Target value $^{\mathrm{b}}$ & 100 & - & - & 200 & 35 & 36 & 140 & - & 0.8 & 85 & 10 & - \\
\hline Intervention value $^{\mathrm{b}}$ & 300 & - & - & 625 & 210 & 190 & 720 & - & 12 & 530 & 200 & - \\
\hline
\end{tabular}

${ }^{\mathrm{a}}$ Mean values of different natural soils of China [21]; ${ }^{\mathrm{b}}$ Values of dutch soil guidelines [22]; ${ }^{\mathrm{c}}$ Background value [15]. 
Dendrogram using Single Linkage

Rescaled Distance Cluster Combine

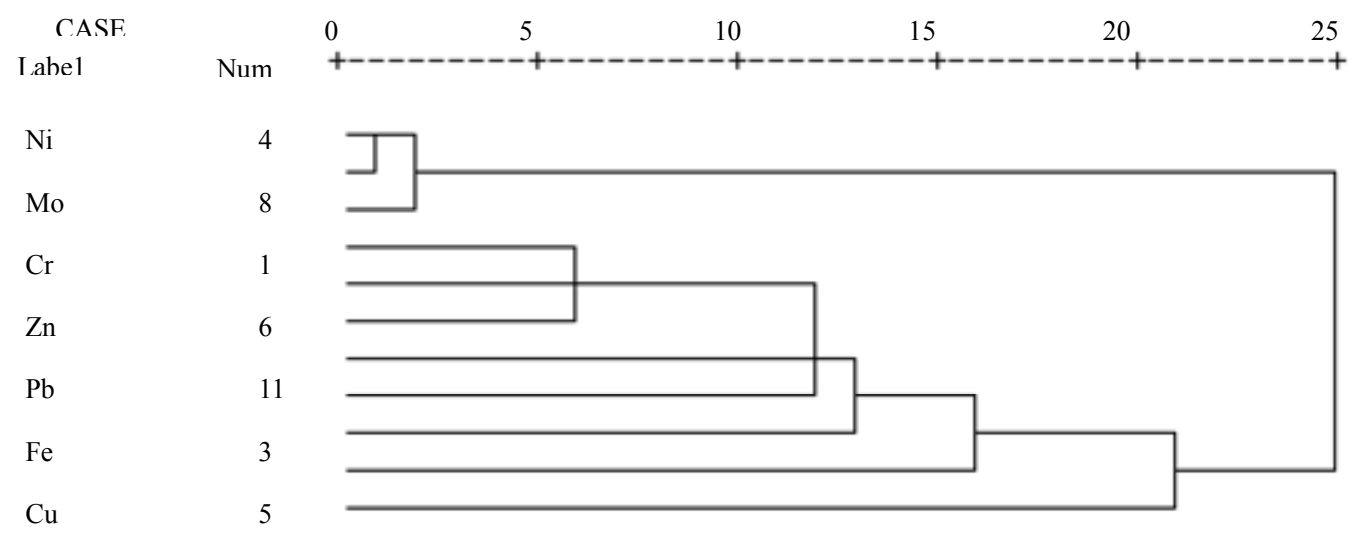

Figure 2. Dendogram of the cluster analysis based on the correlation coefficients using the nearest neighbour linkage method.

Table 2. Values of two extracted factor loadings for the studied heavy metals. Values of dominant elements in each factor reported in bold.

\begin{tabular}{ccc}
\hline & Factor 1 & Factor 2 \\
\hline $\mathrm{Cr}$ & 0.154 & $\mathbf{0 . 9 3 5}$ \\
$\mathrm{Mn}$ & $\mathbf{0 . 5 7 3}$ & 0.132 \\
$\mathrm{Fe}$ & $\mathbf{0 . 8 1 7}$ & 0.054 \\
$\mathrm{Ni}$ & 0.181 & $\mathbf{0 . 9 5 8}$ \\
$\mathrm{Cu}$ & $\mathbf{0 . 7 2 0}$ & 0.177 \\
$\mathrm{Zn}$ & $\mathbf{0 . 8 6 0}$ & 0.155 \\
$\mathrm{Sr}$ & $\mathbf{0 . 6 7 0}$ & 0.098 \\
$\mathrm{Mo}$ & 0.076 & $\mathbf{0 . 9 6 1}$ \\
$\mathrm{Cd}$ & $\mathbf{0 . 6 5 6}$ & 0.061 \\
$\mathrm{Ba}$ & $\mathbf{0 . 4 9 3}$ & 0.093 \\
$\mathrm{~Pb}$ & $\mathbf{0 . 8 8 0}$ & 0.040 \\
$\mathrm{Expl.} \mathrm{Var.}$ & $\mathbf{3 8} \%$ & $\mathbf{2 5} \%$ \\
\hline
\end{tabular}

Extraction method: principal component analysis; Rotation method: varimax with Kaiser normalization. Rotation converged in 3 iterations.

heavy metals in this study area is shown in Figure 3. Similar spatial distribution patterns of $\mathrm{Pb}, \mathrm{Fe}, \mathrm{Zn}$, to a lesser extent, $\mathrm{Cu}, \mathrm{Cd}, \mathrm{Sr}$ and $\mathrm{Mn}$, indicated that their highest concentrations were found in central and northern parts of the urban area. On the other hand, similar distribution patterns were found for $\mathrm{Cr}, \mathrm{Ni}$, and $\mathrm{Mo}$.

In agreement to FA and CA results, the spatial distribution analysis suggests that the increase of $\mathrm{Pb}, \mathrm{Fe}, \mathrm{Cu}$, $\mathrm{Cd}$ and $\mathrm{Zn}$ probably came from a common anthropogenic source. Previous studies have demonstrated that $\mathrm{Zn}, \mathrm{Pb}$ and $\mathrm{Cu}$ in Xuzhou urban topsoils were principally from traffic emissions [1].

The spatial distribution of $\mathrm{Cr}, \mathrm{Ni}$ and Mo suggests that their distribution pattern could be mainly controlled by parent material.

\subsection{Correlation of Specific Susceptibility $(\chi)$ with Heavy Metals}

Table 1 also shows the median value of specific susceptibility in studied area is $157 \times 10^{-8} \mathrm{~m}^{3} / \mathrm{kg}$, ranging from $37 \times 10^{-8} \mathrm{~m}^{3} / \mathrm{kg}$ to $1554 \times 10^{-8} \mathrm{~m}^{3} / \mathrm{kg}$. The mean value of specific susceptibility is significantly higher than its local background value. The spatial distributipn map of specific susceptibility are presented in Figure $\mathbf{4}$ as well. Similar spatial distribution patterns of between $\mathrm{Pb}, \mathrm{Zn}$ and $\chi$ were observed in the map.

To examine the relationships between the heavy metals and mass specific susceptibility, a correlation table (Pearson coefficients) has been established (Table 3). $\mathrm{The} \mathrm{Pb}, \mathrm{Zn}$ and $\mathrm{Fe}$ show strongly significant correlations with magnetic susceptibility $(r>0.7$ and $p<0.01)$, and $\mathrm{Cu}, \mathrm{Cd}, \mathrm{Mn}, \mathrm{Sr}$ and $\mathrm{Ba}$, on the other hand, show a weak correlation with magnetic susceptibility $(r<0.7$ and $\mathrm{p}<$ 0.01). Of these metals, $\mathrm{Cr}, \mathrm{Ni}$ and Mo show no significant correlations to the specific susceptibility. As expected, common presence of some heavy metals from the anthropogenic emissions accounts for the significant correlations between the magnetic susceptibility and these metals in the urban topsoil. Our study suggests that simple, rapid, and nondestructive magnetic measurements could provide useful information about some heavy metal pollution in Xuzhou urban topsoils.

\section{Conclusion}

The heavy metals concentrations in Xuzhou urban topsoils were slightly higher than those of natural soils in 

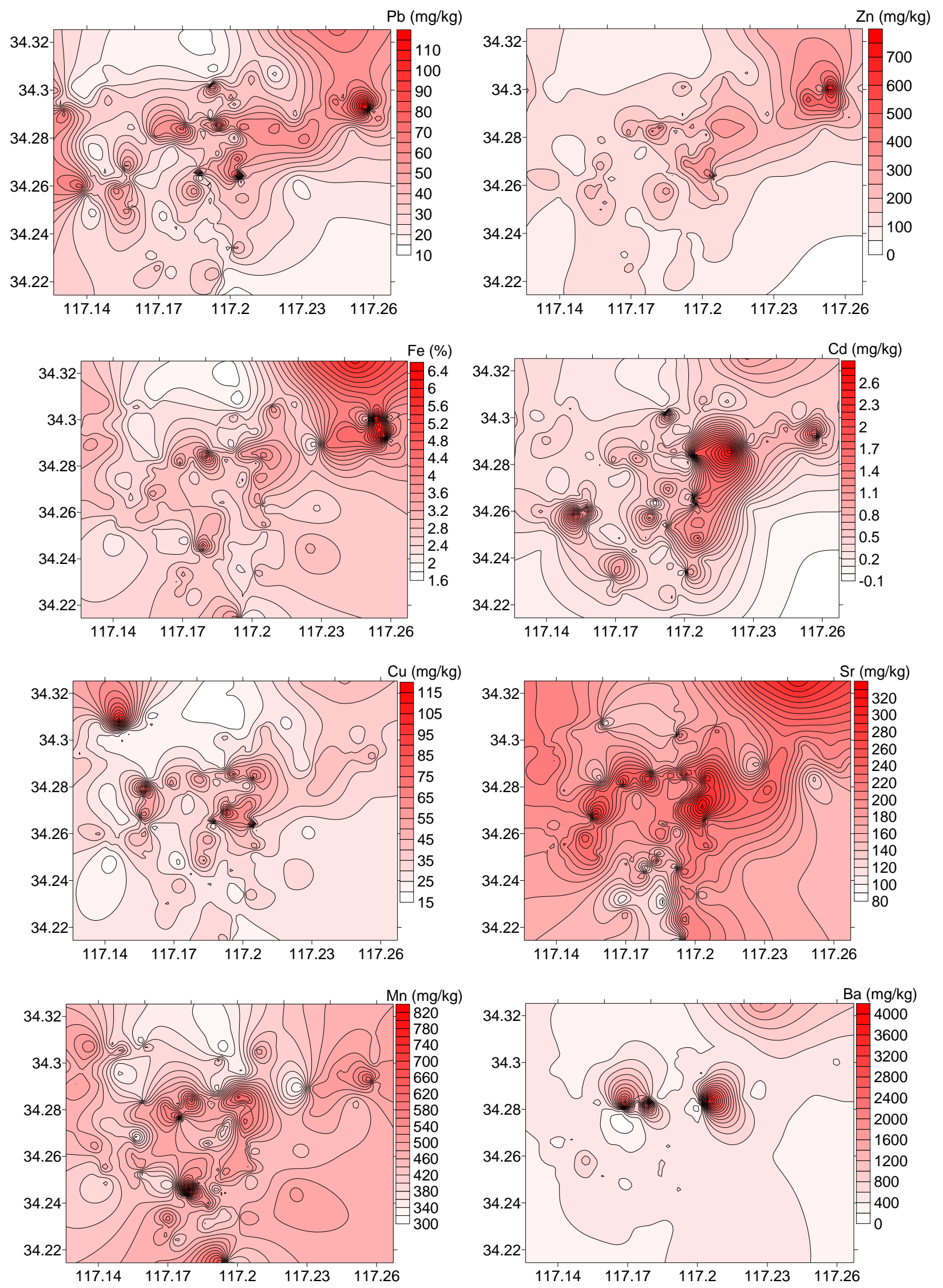

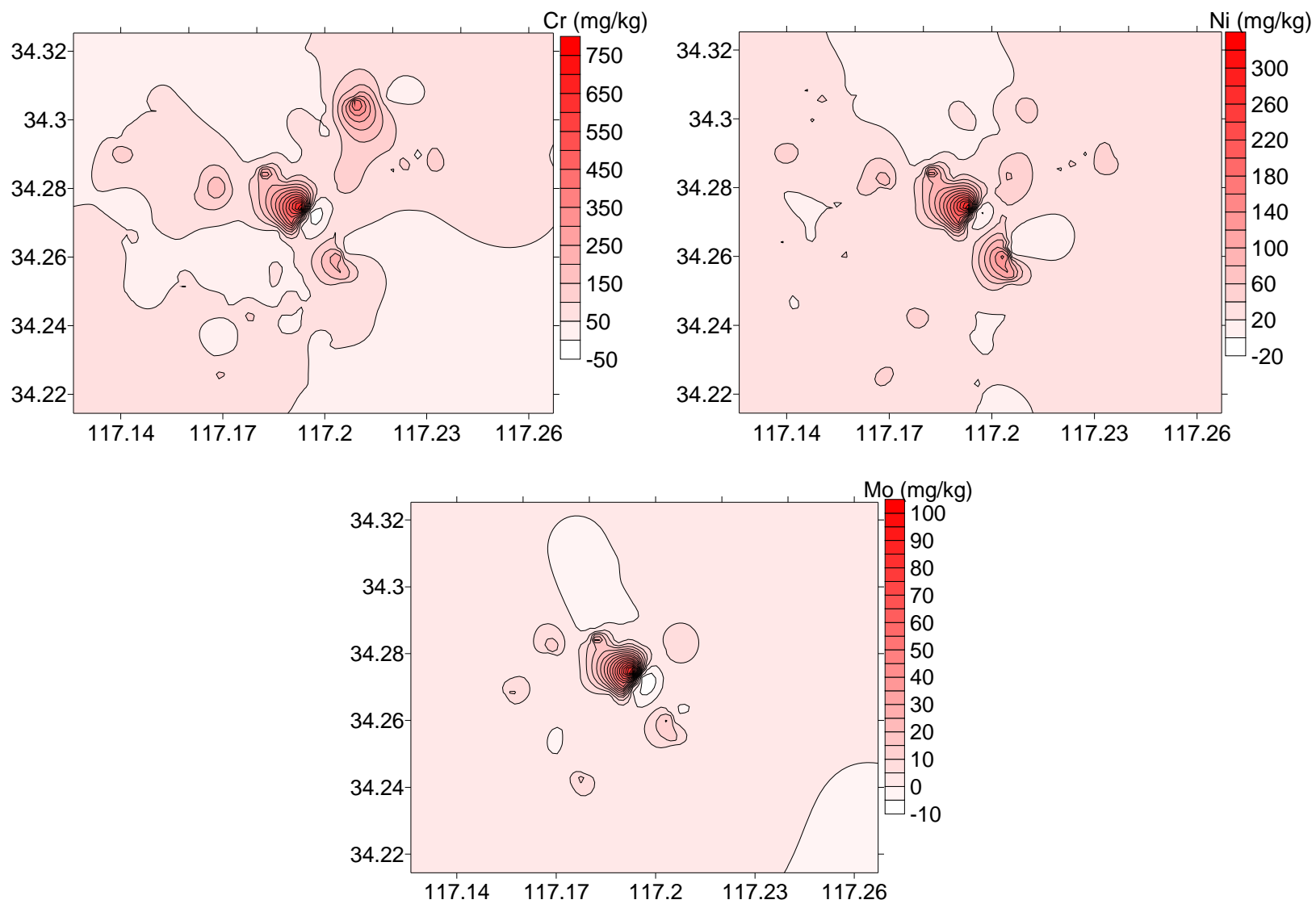

Figure 3. Spatial distribution of the analyzed metals in Xuzhou urban soil.

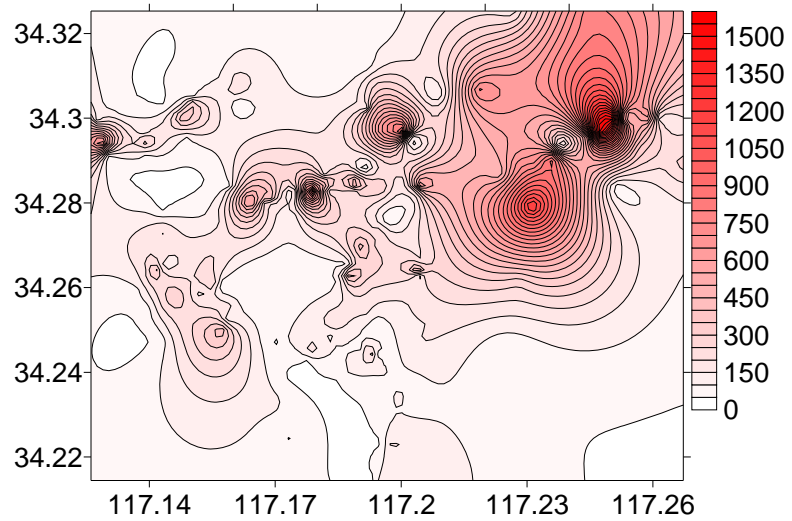

Figure 4. Spatial distribution of the specific susceptibility $(\chi)$ in Xuzhou urban soil.

Table 3. Pearson product-moment correlation coefficient (r) between magnetic susceptibility $\left(10^{-8} \mathrm{~m}^{3} / \mathrm{kg}^{2}\right)$ and concentrations $(\mathrm{mg} / \mathrm{kg})$ of heavy metals in tested soil samples.

\begin{tabular}{|c|c|c|c|c|c|c|c|c|c|c|c|}
\hline & $\mathrm{Cr}$ & $\mathrm{Mn}$ & $\mathrm{Fe}$ & $\mathrm{Ni}$ & $\mathrm{Cu}$ & $\mathrm{Zn}$ & $\mathrm{Cd}$ & $\mathrm{Pb}$ & $\mathrm{Sr}$ & $\mathrm{Ba}$ & Mo \\
\hline$\chi$ & 0.143 & $0.206^{* *}$ & $0.799^{* *}$ & 0.110 & $0.369^{* *}$ & $0.740^{* *}$ & $0.462^{* *}$ & $0.723^{* *}$ & $0.394^{* *}$ & $0.249^{* *}$ & 0.094 \\
\hline
\end{tabular}

${ }^{* *}$ Correlation is significant at the $\mathrm{p}<0.01$ level (two tailed).

China. Results of combined multivariate statistical analyses (FA and CA) and the distribution patterns suggested that heavy metals including $\mathrm{Zn}, \mathrm{Pb}, \mathrm{Fe}, \mathrm{Mn}, \mathrm{Cu}$,
$\mathrm{Cd}, \mathrm{Sr}$ and $\mathrm{Ba}$ were mainly derived from anthropogenic emissions. Significant correlations between $\mathrm{Zn}, \mathrm{Pb}, \mathrm{Fe}$ and $\chi$ suggest that specific susceptibility can serve as 
proxies for these metals levels in Xuzhou urban soils.

\section{Acknowledgements}

The material is based upon work supported by the National Natural Science Foundation of China (20977040).

\section{REFERENCES}

[1] X. S. Wang, Y. Qin and S. X. Sang, "Accumulation and Sources of Heavy Metals in Urban Topsoils: A Case Study from the City of Xuzhou, China," Environmental Geology, Vol. 48, No. 1, 2005, pp. 101-107. doi:10.1007/s00254-005-1270-x

[2] B. Wei and L. Yang, "A Review of Heavy Metal Contaminations in Urban Soils, Urban Road Dusts and Agricultural Soils from China," Microchemical Journal, Vol. 94, No. 2, 2010, pp. 99-107. doi:10.1016/j.microc.2009.09.014

[3] Y. Zheng, T. Chen and J. He, "Multivariate Geostatistical Analysis of Heavy Metals in Topsoils from Beijing, China," Journal of Soils and Sediments, Vol. 8, No. 1, 2008, pp. 51-58. doi:10.1065/jss2007.08.245

[4] P. Guo, Z. Xie, J. Li, C. Kang and J. Liu, "Relationships between Fractionations of $\mathrm{Pb}, \mathrm{Cd}, \mathrm{Cu}, \mathrm{Zn}$ and $\mathrm{Ni}$ and Soil Properties in Urban Soils of Changchun, China," Chinese Geographical Science, Vol. 15, No. 2, 2005, pp. 179-185. doi:10.1007/s11769-005-0013-y

[5] Y. Lu, F. Zhu, J. Chen, H. Gan and Y. Guo, "Chemical Fractionation of Heavy Metals in Urban Soils of Guangzhou, China," Environmental Monitoring and Assessment, Vol. 134, No. 1-3, 2007, pp. 429-439. doi:10.1007/s10661-007-9634-1

[6] M. Zhang and Z. Ke, "Heavy Metals, Phosphorus and Some Other Elements in Urban Soils of Hangzhou City, China," Pedosphere, Vol. 14, No. 2, 2004, pp. 177-185.

[7] Y. Lu, Z. Gong, G. Zhang and W. Burghardt, "Concentrations and Chemical Speciations of $\mathrm{Cu}, \mathrm{Zn}, \mathrm{Pb}$ and $\mathrm{Cr}$ of Urban Soils in Nanjing, China," Geoderma, Vol. 115, No. 1-2, 2003, pp. 101-111. doi:10.1016/S0016-7061(03)00079-X

[8] G. Shi, Z. Chen, S. Xu, J. Zhang, L. Wang, C. Bi and J. Teng, "Potentially Toxic Metal Contamination of Urban Soils and Roadside Dust in Shanghai, China," Environmental Pollution, Vol. 156, No. 2, 2008, pp. 251-260. doi:10.1016/j.envpol.2008.02.027

[9] X. S. Wang and Y. Qin, "Spatial Distribution of Metals in Urban Topsoils of Xuzhou (China): Controlling Factors and Environmental Implications," Environmental Geology, Vol. 49, No. 6, 2006, pp. 905-914. doi:10.1007/s00254-005-0122-Z

[10] F. Li, Z. Fan, P. Xiao, O. Kokyo, X. Ma and W. Hou, "Contamination, Chemical Speciation and Vertical Distribution of Heavy Metals in Soils of an Old and Large Industrial Zone in Northeast China," Environmental Geology, Vol. 57, No. 8, 2009, pp. 1815-1823. doi:10.1007/s00254-008-1469-8
[11] X. Li, C. Poon and P. Liu, "Heavy Metal Contamination of Urban Soils and Street Dusts in Hong Kong," Applied Geochemistry, Vol. 16, No. 11-12, 2001, pp. 1361-1386. doi:10.1016/S0883-2927(01)00045-2

[12] X. Luo, S. Yu and X. Li, "Distribution, Availability, and Sources of Trace Metals in Different Particle Size Fractions of Urban Soils in Hong Kong: Implications for Assessing the Risk to Human Health," Environmental Pollution, Vol. 159, No. 5, 2011, pp. 1317-1326. doi:10.1016/j.envpol.2011.01.013

[13] A. Blundell, J. A. Hannam, J. A. Dearing and J. F. Boyle, "Detecting Atmospheric Pollution in Surface Soils Using Magnetic Measurements: A Reappraisal Using an England and Wales Database," Environmental Pollution, Vol. 157, No. 10, 2009, pp. 2878-2890. doi:10.1016/j.envpol.2009.02.031

[14] E. Petrovsky, A. Kapicka, N. Jordanova, M. Knab and V. Hoffmann, "Low-Field Magnetic Susceptibility: A Proxy Method of Estimating Increased Pollution of Different Environmental Systems," Environmental Geology, Vol. 39, No. 3-4, 2000, pp. 312-318. doi:10.1007/s002540050010

[15] X. S. Wang and Y. Qin, "Correlation between Magnetic Susceptibility and Heavy Metals in Urban Topsoils: A Case Study from the City of Xuzhou, China," Environmental Geology, Vol. 49, No. 1, 2005, pp. 10-17. doi:10.1007/s00254-005-0015-1

[16] H. Fialova, G. Maier, E. Petrovsky, A. Kapicka, T. Boyko, R. Scholger and MAGPROX Team, "Magnetic Properties of Soils from Sites with Different Geological and Environmental Settings," Journal of Applied Geophysics, Vol. 59, No. 4, 2006, pp. 273-283. doi:10.1016/j.jappgeo.2005.10.006

[17] R. Karimi, S. Ayoubi, A. Jalalian, A. R. Sheikh-Hosseini and M. Afyuni, "Relationships between Magnetic Susceptibility and Heavy Metals in Urban Topsoils in the Arid Region of Isfahan, Central Iran," Journal of Applied Geophysics, Vol. 74, No. 1, 2011, pp. 1-7. doi:10.1016/j.jappgeo.2011.02.009

[18] X. S. Wang, P. Zhang, H. Y. Zhou and J. Fu, "Polycyclic Aromatic Hydrocarbons (PAHs) in Urban Topsoils: Concentration and Source Analysis in Xuzhou, China," International Journal of Environmental Studies, Vol. 69, No. 4, 2012, pp. 602-615. doi:10.1080/00207233.2012.693288

[19] X. S. Wang, P. Zhang, H. Y. Zhou and J. Fu, "Association of Black Carbon with Polycyclic Aromatic Hydrocarbons and Heavy Metals in Urban Topsoils and Environmental Implications," International Journal of Environmental Studies, Vol. 69, No. 5, 2012, pp. 705-713. doi:10.1080/00207233.2012.702414

[20] X. Li, S. Lee, S. Wong, W. Shi and I. Thornton, "The Study of Metal Contamination in Urban Soils of Hong Kong Using a GIS-Based Approach", Environmental Pollution, Vol. 129, No. 1, 2004, pp. 113-124. doi:10.1016/j.envpol.2003.09.030

[21] China Environmental Monitoring General Station, "Recent Measuring Methods of Elements in Soils," China Environmental Science Press, Beijing, 1992. 
[22] VROM, "Circular Values and Intervention Values for Soil Remediation Annex A: Target Values, Soil Remediation Intervention Values and Indictive Levels for Se- rious Contamination,” Dutch Ministry of Housing, Spatial Planning and Environment (VROM), 2000. 